\title{
Mediated Learning Experience: Choosing Cognitive Modifiability
}

\author{
Anthony Shay* \\ University of Wisconsin-Stout Vocational Rehabilitation Institute, USA
}

Submission: February 17, 2017; Published: February 21, 2017

*Corresponding author: Anthony Shay, Ed.D., LPC, CRC, University of Wisconsin-Stout Vocational Rehabilitation Institute, 202 Washington St., Westby, WI 54667, USA, Tel no: 608-606-2459; Email: tafts4268@gmail.com

\begin{abstract}
Reuven Feuerstein developed a cognitive modifiability theory he termed Structural Cognitive Modifiability. The process is a multifaceted approach to facilitating intellectual growth for individuals with cognitive deficits. A facet of this process is the mediated learning experience (MLE). The MLE involves a mediator placing themselves between the individual and environmental stimuli and mediating the experience to the individual. A process whereby meaning making occurs and is deliberately reinforced toward the individual's development of selfmediation defined by Feuerstein as reciprocation. An MLE is comprised of three primary elements including intention/reciprocity, mediation of transcendence, and mediation of meaning. Mediational elements such as these form the basis of the adaptability and meaning making we know as intellect.
\end{abstract}

Keywords: Mediated Learning Experience; Adaptability; intelligence; Reuven Feuerstein; Structural Cognitive Modifiability

Abbreviations: MLE: Mediated Learning Experience; SCM: Structural Cognitive Modifiability; FIE: Feuerstein Instrumental Enrichment program; DA: Dynamic Assessment

\section{Introduction}

Adaptive and critical thinking skills are key to effective task engagement. But how do you build these skills in individuals where they are lacking? Reuven Feuerstein [1] suggests a cognitive modifiability process by which achievement is possible [1]. Feuerstein's theory of Structural Cognitive Modifiability ( $\mathrm{SCM}$ ) is the foundation upon which he constructs a multifaceted methodology for building the brain's capacity for modifiability. These facets include Mediated Learning Experience (MLE), Feuerstein Instrumental Enrichment program (FIE), Dynamic (Cognitive) Assessment (DA): The Learning Propensity Assessment Device, and Shaping Mediating Environments. The FIE program is an approach to applying the theoretical principles of SCM and MLE using instruments designed to enhance modifiability in the learner. Through this meta-cognitive process greater skill development through deeper learning is achieved.

Feuerstein [2,3] finds traditional cognitive assessment processes deficient. These assessments offer a static point-intime perspective of cognitive functioning. They do little in the way of accurately delineating a learner's needs, especially for those with significant cognitive challenges $[2,3]$. The DA process is an interactive (mediated) process designed to hone in on these challenges and drives the subsequent mediated learning process. This review focuseson MLE. However, the theoretical approaches stemming from SCM are used to great effect together.

\section{Discussion}

Mediated Learning Experiences emphasize building thinking and learning skills in learners and touts successes in individuals with genetic and socio-cultural challenges alike. MLE seeks to meet learners where they are in their cognitive development with a goal of facilitating capacity building even in those with epistemic challenges. This socio-cultural mediation of the learning process was developed to address the needs of learners suffering from environmental deprivation and trauma (i.e. children who were holocaust survivors), those with disabling genetic conditions, and culturally challenged individuals: "modifiability applies to them and can be applied to a wide and diverse range of human conditions" [2]. For MLE to have an opportunity for success, learners must choose modifiability. "Effort and resources" are necessary for change to occur but "not everyone actualizes this ability" [2]. Three 
barriers to modifiability exist, according to Feuerstein: etiology, age of onset, and severity of condition. These address the cause of the condition (or impairment); the age at which the condition is recognized and subsequent intervention begins; and the severity and number of concomitant impairments and conditions [2]. Feurstein et al. [2] state that individuals with "the need, belief, intention, and the proper tools" can overcome barriers to modifiability [2].

Feuerstein draws a distinction between teaching and mediating. Teaching involves the transmission of knowledge whereas mediation involves moving past the initial transmission of knowledge to the application of the knowledge to real-world experiences and the development of greater meaning [2]. Teachers may also be mediators; however, the distinction seeks to clarify the difference between passive or incidental interaction and purposeful interaction. In fact, Feuerstein states explicitly that awareness is an essential component of a mediational interaction producing an effective change in a mediatee-the mediation of the content of the learning, its significance, and why it has significance. In other words, intentionality and reciprocity (Feuerstein, Falik, \& Feuerstein, 2015HYPERLINK “" \l "_ftn1" $\backslash$ o “” [1]). This is contrasted by direct learning experiences whereby a learner experiences the context, tasks, and work related activities directly and without any intermediation.

There are many features which may comprise a MLE. In fact, Feuerstein expects these to continue to be identified and for them to evolve over time. However, he suggests that there are three primary features of a mediated learning experience. These necessary components of an MLE include intention/ reciprocity, mediation of transcendence, and mediation of meaning $[2,3]$. An interaction cannot be mediational without these three features. They must be provided in a measured and organized manner. Intention and reciprocity refers to an active two-way engagement between the learner and the mediator. There is no passive or incidental interaction (i.e. the mediation is deliberate). This engagement reflects less a focus on the learner or the task than on their cognitive processes; the learner shares in the mediator's cognition toward application of the learning in the mediator's absence (i.e. reciprocity or self-mediation) [2]. Transcendence reflects the mediating purpose (the task learning activity driving the mediating effort) and the generalization of the learning outward-building the capacity to map meaning onto other experiential activities and tasks [5]. The idea is that direct learning is not necessarily discouraged; rather, mediated experiences drive the development of self-directed meaning making: [learners] forge in them a repertoire of dispositions, propensities, orientations, attitudes, and techniques that enable them to modify themselves in relation to other stimuli...MLE produces the plasticity and flexibility of adaptation that we call intelligence [3].

Meaning is derived through the mediator's efforts to engage the learner and create a positive learning environment. Through this process the mediator facilitates meaning making through placing themselves between the learner and the stimulus. As the learner develops meaning and begins the process of selfmediation the MLE fades [5].

\section{Conclusion}

Environments which reflect rote behavior bereft of meaning and value have no mediational capacity $[2,6]$. The effectiveness of an interaction between the self and the environment is what defines a mediated learning experience [3]. Feuerstein finds that only a human being can be a mediator due to the unequivocal need for intentionality [4]. In a MLE mediators place themselves between the learner and the context. Task and work related activity is purposefully mediated to the learner, through the mediator, with the intention of building skills and mapping these to other tasks and activities.

\section{References}

1. Dawes G (2006) Getting the brain into gear: Reuven Feuerstein and structural cognitive modifiability. Development and Learning in Organizations: An International Journal 20(3): 18-20.

2. Feuerstein R, Feuerstein RS, Falik LH (2010) Beyond Smarter: Mediated Learning and the Brain's Capacity for Change. Teacher's College Press, New York, USA.

3. Feuerstein R (2015) The theory of structural cognitive modifiability and mediated learning experience. Feuerstein Institute.

4. Feuerstein R, Falik LH, Feuerstein RS (2015) Changing Minds \& Brains: The Legacy of Reuven Feuerstein. Teacher's College Press, New York, USA.

5. Feuerstein R, Lewin-Benham A (2012) What learning looks like: Mediated learning in theory and practice, K-6. Teacher's College Press, New York, USA.

6. Kozulin A, Presseisen BZ (1995) Mediated learning experience and psychological tools: Vygotsky's and Feuerstein's perspectives in a study of student learning. Educational Psychologist 30(2): 67-75. 
Your next submission with Juniper Publishers will reach you the below assets

- Quality Editorial service

- Swift Peer Review

- Reprints availability

- E-prints Service

- Manuscript Podcast for convenient understanding

- Global attainment for your research

- Manuscript accessibility in different formats ( Pdf, E-pub, Full Text, Audio)

- Unceasing customer service

Track the below URL for one-step submission https://juniperpublishers.com/online-submission.php 